\title{
Towards advanced sodium-ion batteries: green, low-cost and high- capacity anode compartment encompassing phosphorus/carbon nanocomposite as the active material and aluminum as the current collector
}

To cite this article before publication: Eliana Quartarone et al $2020 \mathrm{~J}$. Electrochem. Soc. in press https://doi.org/10.1149/1945-7111/ab856e

\section{Manuscript version: Accepted Manuscript \\ Accepted Manuscript is "the version of the article accepted for publication including all changes made as a result of the peer review process, and which may also include the addition to the article by IOP Publishing of a header, an article ID, a cover sheet and/or an 'Accepted} Manuscript' watermark, but excluding any other editing, typesetting or other changes made by IOP Publishing and/or its licensors"

This Accepted Manuscript is @ 2020 The Author(s). Published by IOP Publishing Ltd.

This article can be copied and redistributed on non commercial subject and institutional repositories.

Although reasonable endeavours have been taken to obtain all necessary permissions from third parties to include their copyrighted content within this article, their full citation and copyright line may not be present in this Accepted Manuscript version. Before using any content from this article, please refer to the Version of Record on IOPscience once published for full citation and copyright details, as permissions will likely be required. All third party content is fully copyright protected, unless specifically stated otherwise in the figure caption in the Version of Record.

View the article online for updates and enhancements. 
Towards advanced sodium-ion batteries: green, low-cost and high-capacity anode compartment encompassing phosphorus/carbon nanocomposite as the active material and aluminum as the current collector

\begin{tabular}{|r|l|}
\hline Journal: & Journal of The Electrochemical Society \\
\hline Manuscript ID & JES-100860.R1 \\
\hline Manuscript Type: & Research Paper \\
\hline Author: & 24-Mar-2020 \\
\hline Complete List of Authors: & $\begin{array}{l}\text { Quartarone, Eliana; University of Pavia, Chemistry } \\
\text { Kuenzel, Tobias; Karlsruher Institut fur Technologie } \\
\text { Kuenzel, Matthias; Karlsruher Institut fur Technologie } \\
\text { Tealdi, Cristina; University of Pavia } \\
\text { marrani, andrea; University of Rome La Sapienza } \\
\text { Brutti, Sergio; University of Rome La Sapienza, Department Of } \\
\text { Chemistry } \\
\text { Callegari, Daniele; University of Pavia } \\
\text { Passerini, Stefano; Karlsruhe Institute of Technology, Helmholtz Institute } \\
\text { Ulm }\end{array}$ \\
\hline Topical Keywords: & Batteries, Batteries - Lithium, Energy Storage \\
\hline &
\end{tabular}




\title{
Towards Advanced Sodium-Ion Batteries: Green, Low-Cost and High-Capacity Anode Compartment Encompassing Phosphorus/Carbon Nanocomposite as the Active Material and Aluminum as the Current Collector
}

\author{
E. Quartarone, ${ }^{1, z}$ T. Eisenmann,,${ }^{2,3}$ M. Kuenzel,,${ }^{2,3}$ C. Tealdi, ${ }^{1}$ A. G. Marrani, ${ }^{4}$ S. Brutti, ${ }^{4, *}$ D. \\ Callegari, ${ }^{1}$ and S. Passerini ${ }^{2,3, *}$ \\ ${ }^{1}$ Department of Chemistry and INSTM, University of Pavia, 27100 Pavia, Italy \\ ${ }^{2}$ Helmholtz Institute Ulm (HIU), 89081 Ulm, Germany \\ ${ }^{3}$ Karlsruhe Institute of Technology (KIT), 76021 Karlsruhe, Germany \\ ${ }^{4}$ Department of Chemistry, University of Rome La Sapienza, Piazzale Aldo Moro, Roma, Italy \\ *Electrochemical Society Member. \\ ${ }^{\mathrm{z} E-m a i l: ~ E l i a n a . q u a r t a r o n e @ u n i p v . i t ~}$
}

\begin{abstract}
Sodium-ion batteries (SIBs) are promising alternative to Lithium-ion batteries for massive
\end{abstract} stationary energy storage. To improve energy density, however, more performing active materials are needed. In order to allow sustainable scale-up, it is also mandatory to develop green products and processes. Herein, we report on anodes of phosphorus/carbon $(\mathrm{P} / \mathrm{C})$ nanocomposites prepared via High Energy Ball Milling (HEBM), a simple, powerful and easily scalable synthesis technique. The electrodes were prepared under oxygen-free atmosphere, using water as solvent, which enabled the use of aluminum (instead of copper) as current collector, implying significant cost reduction. The P/C nanocomposite obtained after 54 hours HEBM resulted in excellent cycling stability, delivering very high specific capacity (2200 $\left.\mathrm{mAh} \mathrm{g}^{-1}, \mathrm{C} / 20\right)$ and showing good capacity retention after 120 cycles. A careful structural analysis (XRD, FESEM-EDS, XPS), revealed that long milling times strongly increased cycling stability due to: i) significant decrease of $\mathrm{P}$ particle size inside the matrix and deep composite amorphization, which alleviates the buffering dimensional issues typical of black phosphorus; ii) presence of defects in the carbonaceous component, which allows easier $\mathrm{Na}^{+}$insertion into the anode. Our results show that P/C nanocomposites are very promising anode materials for SIBs, paving the way for further exploitation of nano-architectures in SIBs technology.

\section{Introduction}


Lithium-ion batteries (LIBs) are nowadays the technology of choice for electrochemical energy storage devices because of their high energy density, being one of the key criteria in portable devices and electric vehicles [1-3]. Sodium-ion batteries (SIBs) are considered one of the most promising candidates for stationary energy storage due to high crustal abundance and low cost of sodium resources. In particular, the possibility of using aluminum as current collector has been shown to drastically reduce production cost of SIBs [4]. Nevertheless, active materials need to be improved in terms of specific and volumetric capacity, in order to be compatible with state-of-the-art LIBs.

Among a variety of potentially promising anode materials for SIBs, phosphorus $(\mathrm{P})$ ís considered particularly attractive because of its high theoretical capacity $\left(2596 \mathrm{~mA} \mathrm{~h} \mathrm{~g}^{-1}\right)$ and abundant reserves. Phosphorus possesses three main allotropes: white, red and black. From an electrochemical point of view, both red $\mathrm{P}(\mathrm{RP})[5,6]$ and black $\mathrm{P}(\mathrm{BP})$ are attractive [7, 8], but BP generally offers better electrochemical performance due to its higher electronic conductivity compared to RP $\left(10^{2} \mathrm{~S} \mathrm{~m}^{-1} \mathrm{vs}\right.$ $\left.10^{-12} \mathrm{~S} \mathrm{~m}^{-1}\right)[7,8]$.

Black phosphorus (BP) has an orthorhombic crystalline structure, consisting of puckered double layers with parallel zig-zag chains of interconnected, $\mathrm{sp}^{3}$ hybridized $\mathrm{P}$ atoms. The final structure is made up of $\mathrm{P}_{6}$ rings in a chair conformation. The individual layers are stacked and held together by weak Van der Waals forces creating the bulk BP 2D multilayer structure. This 2D arrangement allows the intercalation of e.g., $\mathrm{Li}^{+}, \mathrm{Na}^{+}$and $\mathrm{K}^{+}[8]$ in the discharge potential range between $1.2 \mathrm{~V}$ and 0.4 V. At lower potentials, the high specific capacity is achieved due to the three electron transfer, alloying-like reaction of $\mathrm{P}$ with $\mathrm{Li}^{+}$and $\mathrm{Na}^{+}$to form $\mathrm{Li}_{3} \mathrm{P}$ or $\mathrm{Na}_{3} \mathrm{P}$ in case of LIBs and SIBs, respectively [6-8]. Furthermore, intrinsic anisotropic properties of BP can tune morphological evolution and mitigate strain during sodiation [11].

In case of SIBs, BP based materials have been studied widely as a high capacity alternative to state-of-the-art hard carbons (around $250-300 \mathrm{mAh} \mathrm{g}^{-1}$ ). Some P/C composites described in literature deliver specific capacities exceeding $1500 \mathrm{mAh} \mathrm{g}^{-1}$, depending on the electrolyte composition as well as the type and amount of carbon used [12-14]. However, despite the high initial capacities reported, capacity retentions are poor and the cells show capacity fading already after a few cycles due to severe and irreversible volume expansion (more than $300 \%$ ) upon cycling. Several attempts were reported to mitigate the degradation of BP and to improve the overall cyclability, as for instance (i) the use of fluoroethylene carbonate (FEC) additive in the electrolyte to form a more stable SEI, (ii) an upper cut-off potential of $0.8 \mathrm{~V}\left(\mathrm{vs} \mathrm{Na}^{+} / \mathrm{Na}\right)$ to enhance reversibility [12-14] or (iii) the use of large amounts of conductive carbon to buffer the volume expansion during cycling. The latter was mostly achieved by producing $\mathrm{P} / \mathrm{C}$ nanocomposites from red phosphorus and carbon via 
high energy ball milling, often alongside the direct phase transformation of red to black phosphorus $[7,15,16]$. The extent of the phase transformation depends on experimental parameters, such as the spheres/material ratio, rotation speed and milling time] [17].

The optimized phosphorus/carbon mass ratio was determined to be 7/3 w/w [7]. G.-L. Xu et al. prepared nanostructured BP-MWCNT (multi-walled carbon nanotubes) composite anodes for SIB by high energy ball milling which delivered specific capacities of around $1700 \mathrm{mAh} \mathrm{g}^{-1}$ for 100 cycles at relatively high charge/discharge rates [18]. Similar performance was observed in case of other composites such as BP-Super P, BP-graphene [19] or BP-MWCNTs including a cross-línked binary binder (poly acrylic acid - carboxymethyl cellulose sodium salt, PAA-NaCMC) [20]. The extent of improved electrochemical performance in these studies is dependent on parameters such as electrode morphology, microstructure and chemical interactions among the components. It was demonstrated, for instance, that in case of nanostructured composites, the rate capability is significantly improved [18]. Several spectroscopic investigations recently proved the presence of strong P-O-C and even P$\mathrm{C}$ bonds which seems to facilitate the (de-)sodiation in $\mathrm{P} / \mathrm{C}$ anodes. The proposed mechanism suggests that such stable crosslinking units form three-dimensional networks with well interconnected covalent bonds, which could enhance the anode mechanical properties and create highly conductive pathways. The consequent result is an elastic buffer that accommodates the severe volume expansion during the reversible sodium insertion/extraction process and enhances the electron conduction, thereby delivering better electrochemical performances. [19, 20, 21] .

A much less addressed issue of $\mathrm{P}$-based active materials is their instability towards air/ $\mathrm{O}_{2}$ and the release of phosphoric acid [22, 23], making them incompatible with aluminum foil as current collector. However, one of the most significant cost reduction factors of SIBs over conventional LIBs is the possibility of using $\mathrm{Al}$ foil as current collector for the anode, due to the slightly higher redox potential of $\mathrm{Na} / \mathrm{Na}^{+}$compared to $\mathrm{Li} / \mathrm{Li}^{+}$and, hence, the prevention of alloy formation [4]. Nevertheless, most studies in common literature report phosphorus-based anode materials for sodium-ion batteries on copper foil as current collector. To our best knowledge, only one work in literature reports on the electrochemistry on $\mathrm{P}$ anodes on $\mathrm{Al}$, describing composite electrodes based on black P/acetylene black. However, this article was not focused on the stability issue and/or optimization aspects concerning the use of $\mathrm{Al}$ as current collector [12].

Herein, we investigate the microstructural and electrochemical properties of composite P/C anodes for Na-ion cells, synthetized via high energy ball milling at constant spheres/material ratio and different milling times ( 2 hours and 54 hours). The electrochemical performance is compared to the one of pure BP electrodes to determine the role of $\mathrm{C}$ in the sodium storage mechanism. To gain 
insights into the structure-property correlation, the anodes were characterized by $\mathrm{X}$ rays diffraction (XRD), Field-Emission Scanning Electron Microscopy and Energy-dispersive X-ray Spectroscopy (FE-SEM/EDX), X-ray Photoelectron Spectroscopy (XPS) and post-mortem SEM-FIB/EDX analysis. Finally, electrode processing was performed with aqueous-based slurries and under exclusion of air, in order to allow the use of aluminum at the current collector.

\section{Experimental}

\subsection{Synthesis of Black Phosphorus}

Black Phosphorus (BP) was synthetized starting from commercial red Phosphorus (RP) (Sigma Aldrich, >97\%) by means of High Energy Ball Milling (HEBM), as described in detail in ref.17. In summary, proper amounts of red $\mathrm{P}$ were inserted in sealed stainless-steel jars with spheres/powder ratios $(\zeta)$ of 40/1 and 110/1, and milled at $500 \mathrm{rpm}$ for 2 hours. Similarly, composites of Phosphorus and conductive Carbon (P/C) were prepared via HEBM of red Phosphorus and C-Nergy Super C65 (Imerys) in a weight ratio 7/3. The milling rate and the spheres/powder ratio $(\zeta)$ were $500 \mathrm{rpm}$ and 30/1, respectively. Two significantly different milling times were chosen, 2 hours (BC_2h) and 54 hours (BC_54h). However, a control sample obtained with an intermediate milling time of 5 hours (BC_5h) was also prepared and preliminary characterized to better investigate the mixing time effect on the structure and electrochemistry of P/C composite anodes.

The manipulation of the products (jar filling and emptying) before and after the synthetic process was carried out in a glove box under Ar atmosphere (UniLab-MBraum, $\mathrm{H}_{2} \mathrm{O}$ and $\mathrm{O}_{2}$ levels $<0.1 \mathrm{ppm}$ ).

\subsection{Electrode preparation}

Electrode slurries were prepared by mixing $50 \mathrm{wt}-\%$ of active material (BP or P/C), 30\% Super C65 and 20\% binder (Na-CMC and PAA in a weight ratio of 1:1 dissolved in deionized water) in a planetary ball mill at $200 \mathrm{rpm}$ for $2 \mathrm{~h}$, followed by a $10 \mathrm{~min}$ break and another $2 \mathrm{~h}$ of milling in reverse direction. The solid content of all slurries was kept between $12 \%$ and $15 \%$. After ball milling, the slurries were casted on aluminum foil (UACJ) using a doctor blade at the speed of $50 \mathrm{~mm} \mathrm{~s}^{-1}$ and a wet film thickness of $100 \mu \mathrm{m}$ and immediately dried under vacuum at $80^{\circ} \mathrm{C}$ for 1 hour. The resulting mass loadings ranged between $1.1 \mathrm{mg} \mathrm{cm}^{-2}$ and $1.5 \mathrm{mg} \mathrm{cm}^{-2}$. The whole process of electrode preparation was conducted without exposition to $\mathrm{O}_{2}$, by de-aerating water for the slurry preparation and avoiding ambient atmosphere to reduce any oxygen contamination and to ensure better compatibility with the aluminum current collector. 


\subsection{Electrochemical characterization}

Round disc electrodes with a diameter of $12 \mathrm{~mm}$ were cut and dried at $100{ }^{\circ} \mathrm{C}$ in vacuum for $12 \mathrm{~h}$. All electrochemical measurements were performed in Swagelok ${ }^{\circledR}$ type three-electrode cells assembled in an Ar-filled glove box (levels for $\mathrm{H}_{2} \mathrm{O}$ and $\mathrm{O}_{2}$ below $0.1 \mathrm{ppm}$ ). Na metal was used both as reference and counter electrode. Electrodes were separated with a Whatman glass fiber separator, soaked in a solution of $1 \mathrm{M} \mathrm{NaPF}_{6}$ in EC:PC (ethylene carbonate-propylene carbonate, 50:50 wt.-\%) with 2 wt.-\% FEC and 5 wt.-\% NaTFSI $(200 \mu \mathrm{L})$. Cells were galvanostatically cycled on a Maccor Series 4000 battery cycler from $0.02 \mathrm{~V}$ to $2 \mathrm{~V}$. All potentials reported refer to the $\mathrm{Na} / \mathrm{Na}^{+}$quasireference couple. Electrochemical Impedance spectroscopy (EIS) was also carried out on sodium half-cell with P/C composite as anode at OCV before and after the galvanostatic cycling at C/20. Nyquist plots were collected in the frequency range $100 \mathrm{KHz}-10 \mathrm{mHz}$ at $50 \mathrm{mV}$ as voltage amplitude and $4 \mathrm{~s}$ as integration time.

\subsection{Methods}

X-ray Diffraction Patterns (XRDP) of the active materials (P-40:1, P-110:1, BC_2h and BC_54h) were collected by means of a Bruker Advance D8 diffractometer $(\mathrm{Cu}-\mathrm{K} \alpha: \lambda=0.154 \mathrm{~nm})$ using an Al sample holder. The data was acquired in the $2 \theta$ range from 10 to 60 , with scan step of 0.02 and a fixed counting time per step of $4 \mathrm{~s}$.

XP spectra were recorded using a modified Omicron NanoTechnology MXPS system equipped with a monochromatic X-ray source (Omicron XM-1000) and an Omicron EA-127 energy analyzer. The exciting radiation was $\mathrm{Al} \mathrm{K} \alpha(\mathrm{hv}=1486.7 \mathrm{eV})$, generated operating the anode at $14-15 \mathrm{kV}$ and 10-20 mA. The experimental spectra were reconstructed by fitting the secondary electrons' background to a Shirley function and the elastic peaks to pseudo-Voigt functions described by a common set of parameters (position, FWHM, Gaussian-Lorentzian ratio) free to vary within narrow limits. During the fitting procedures the Gaussian- Lorentzian ratio was left free to vary between 0.6 and 0.9 .

Field Emission-SEM experiments (FESEM) were carried out on the active materials (BP and $\mathrm{P} / \mathrm{C}$ ) by a Zeiss Auriga electron microscope equipped with a field emission source and a Bruker energy dispersive X-ray spectroscopy (EDS) probe. SEM experiments were carried out by a PHILIPS-FEI XL 30 ESEM instrument equipped with san EDS probe.

Focused-ion beam - Scanning electron microscopy (FIB-SEM) of the pristine and cycled electrodes were performed on a Zeiss Crossbeam 340 field-emission electron microscope, equipped with a Capella focused ion-beam (FIB, gallium ion source). EDX maps were acquired with an energy 
dispersive X-ray (EDX) spectrometer (Oxford Instruments X-Max Xtreme, 100 mm², 1-5 kV). Cycled electrodes were recovered in an Ar filled glove box, carefully rinsed with DMC and transferred to the microscope under Ar atmosphere in a specially designed transfer box (Sample Transfer Shuttle, SEMILAB). Micrographs were acquired from the top, under a tilt-angle of $54^{\circ}$ and in cross-sectional configuration after FIB preparation using smartSEM software for tilt correction to compensate for the image distortion due to the tilt of $54^{\circ}$ to the optical axis. To avoid strong curtaining and sample damage, low currents of $15 \mathrm{nA}$ and $1.5 \mathrm{nA}$ at an acceleration voltage of $30 \mathrm{kV}$ were chosen to mill and polish the cross-sections, respectively.

\section{Results and discussions}

\subsection{Synthesis, structure and morphology of pure BP and composite P-C composites}

Pure BP and P-C composites were synthetized starting from commercial red phosphorus (RP), which was ball milled as pure or mixed with proper amount of Super C65 (7/3 w/w P/C) at $500 \mathrm{rpm}$ by changing the milling time $t$ and ball/powder ratio $\zeta$. Four samples were produced: i) two pure phosphorus samples, both milled for $t=2$ hours with $\zeta=40: 1$ and 110:1, (labelled as P_40:1 and P_110:1, respectively); ii) two P-C composites, obtained at two different milling times ( $t=2$ hours and $t=54$ hours) and $\zeta=30: 1$ (labelled in the following as BC_2h and BC_54h).

Figure 1 shows the XRDP acquired on the two BP samples (a) and on the composites P/C (b). For comparison, the XRDP of commercial RP and of the mechanical mixture RP/C prior to HEBM are included in the two panels, respectively. Commercial red phosphorus is characterized by broad peaks centered at around $15^{\circ}$ and $32^{\circ}$ degrees in $2 \theta$ (PDF 44-0906); crystalline black phosphorus can be indexed according to the orthorhombic phase, crystallizing in the Cmca space group (PDF 74-1878). $\mathrm{RP}$ is famous for its amorphous structure, but it has been shown to adopt also different crystalline modifications [24]. In particular, two crystalline structures are recognized as Hittorf's violet phosphorus and fibrous red phosphorus [25]. The structure reported in PDF card 44-0906 is indexed as monoclinic, in the $P 2 / C$ space group, and has been variously named as "red phosphorus", "violet Hittorf phosphorous", or "red Hittorf phosphorus". In case of pure BP, ball milling conditions were chosen to obtain one sample of fully crystalline BP and a second one containing roughly $20 \%$ of unconverted RP [17]. As discussed in detail in our previous work [17], the HEBM experimental parameters may be varied to modulate the RP-BP conversion. As the balls/powder ratio increases, the degree of RP $\rightarrow$ BP conversion increases. Figure 1a depicts this conversion with a decrease of the main reflection of $\mathrm{RB}\left(15.61^{\circ} 2 \theta\right)$ and an increase of the first reflection of $\mathrm{BP}\left(17.02^{\circ} 2 \theta\right)$ for $\mathrm{P}-110: 1$, 
in contrast to P-40:1. A detailed quantification of the RP/BP ratio as a function of HEBM parameters is reported in ref 17 . Figure $1 \mathrm{~b}$ shows the comparison between the XRD patterns of the two P/C composites. BC_2h depicts a XRD pattern very similar to that of pure BP - 40:1 (see Fig.S1a for a direct comparison), suggesting that both samples have a similar mixture of RP and BP. The P/C composite ball milled for a longer time (54h, BC_54h), however, shows a very different XRD pattern compared to a pure phosphorus reference sample prepared under the same ball mill conditions (see Fig.S1b for a direct comparison). While pure phosphorus ball milled for $54 \mathrm{~h}$ (P-30:1-54h) shows the sharp reflections assigned to crystalline BP (again indicating a mixture of RP and BP), they are absent in the pattern of the composite (BC_54h). It is difficult to discern, however, based on the present data, whether the very broad peaks of BC_54h are due to amorphization of the BP component or due to the formation of a novel phase.

The morphology and surface composition of the two P/C composite materials have been investigated by FE-SEM/EDS as shown in the Figure 2.

Both SEM micrographs (Figure 2a,b) show secondary irregular aggregates of linear sizes in the range of 50-300 and 150-500 $\mathrm{nm}$ for the two P/C-composite materials ball milled 2 and 54 hours, respectively. These secondary aggregates are constituted by similar, smaller nanoparticles of about 10-30 nm, embedded in a smooth outer material. This suggests an increasing agglomeration of primary particles by ball milling and, thus, forming larger secondary aggregates.

At low magnification the composition analysis of the materials surfaces by EDS highlights a C/P atomic ratio of $1.5 \pm 0.3$ and $1.1 \pm 0.3$ for the two $\mathrm{P} / \mathrm{C}$ - composite materials ball milled 2 and 54 hours, respectively. These values are in good agreement with the expected $\mathrm{C} / \mathrm{P}=1.1$ molar ratio derived from the 3/7 weight ratio used for the synthesis. On the other hand, the FE-SEM/EDS combined areal maps highlight a different dispersion of the elements on the materials surfaces. In fact, the C/P intermixing is much more homogeneous in the sample ball milled for $54 \mathrm{~h}$ compared to the one ball milled for 2 $\mathrm{h}$, which shows isolated $\mathrm{P}$-rich and C-rich areas.

The outer surfaces of the powder samples have been investigated by XPS as shown in the Figure 3.

The surface of both samples is constituted by a mixture of carbon, phosphorous and oxygen (see Figure $3 \mathrm{a}$ ). In consideration of the limited penetration of the X-ray beam (2-3 nm in carbonaceous materials), the presence of oxygen is likely related to the pristine materials impurities and to the minor, unayoidable contamination of the samples [26]. 
The C/P atomic ratio derived from the XPS intensities decreases upon increasing the ball milling time, from 2.01 to 1.25 for the two P/C-composite materials ball milled 2 and 54 hours, respectively. The $\mathrm{C} / \mathrm{P}$ value after $54 \mathrm{~h}$ of ball milling is in close agreement with the EDS value and the expected 1.1 molar ratio. This trend is likely related to the more intimate mixing of the constituents and to the more extended nanosizing of $\mathrm{P}$ particles promoted by ball milling.

Experimental XP spectra and its corresponding theoretical reconstruction in the C 1s, P 2p and $\mathrm{O} 1 \mathrm{~s}$ regions are shown in the Figures $3 \mathrm{~b}, 3 \mathrm{c}$ and $3 \mathrm{~d}$, respectively. In both cases the $\mathrm{C} 1 \mathrm{~s}$ peak can be fitted by two major components centered at 284.4 and $284.8 \mathrm{eV}$. Their relative intensities, however, are reversed. The component centered at $284.4 \mathrm{eV}$ is typical of $\mathrm{sp}^{2}$ graphite-like carbons [27], whereas the signal at slightly higher energy $(284.8 \mathrm{eV})$ is commonly attributed to "defective graphite" [28]. Thus, the reversal of the $\mathrm{C}_{\mathrm{sp} 2} / \mathrm{C}_{\text {defective-graph }}$ peaks ratio at longer milling time confirms the expected incorporation of defects in the graphitic structure of the pristine Super C carbon particles [29]. Besides these two main components, other minor signals are found and fitted in both samples at $283.7 \mathrm{eV}$ and in the 285-289 eV range. The component at binding energies $<284 \mathrm{eV}$ can be attributed to carbonphosphides (or phosphorous-carbides, C-P) as already observed by Capone and co-workers [30] and, thus, suggesting the formation of interphases between the phosphorous particles and the surrounding carbon matrix. Remarkably the C-P signal is almost unaltered when the milling time is increased from 2 to $54 \mathrm{~h}$. This trend is in line with the negligible evolution of the components at binding energies > $285 \mathrm{eV}$ upon milling due to oxidized carbon species.

The reconstructions of the phosphorous $2 \mathrm{p}$ peak in the XPS spectra of the two samples match the results in the $\mathrm{C} 1 \mathrm{~s}$ region. The $\mathrm{P} 2 \mathrm{p}$ region shows three doublet peaks (i.e. $3 / 2$ and $1 / 2$ components of the $2 \mathrm{p}$ signal) at $129.9,130.3$ and $134.5 \mathrm{eV}$. The first doublet can be attributed to elemental phosphorous (P-P direct bonds) whereas the second doublet to the C-P interphases already observed in the $\mathrm{C} 1 \mathrm{~s}$ region. The comparison between BC_2h and BC_54h suggests that both components are not modified by extensive ball milling. The third component at binding energies $>134 \mathrm{eV}$ is likely due to the overlapping of many peaks related to oxidized phosphorous species (P-O bonds).

The $\mathrm{O} 1 \mathrm{~s}$ spectral region is unaltered upon ball milling, alike the $\mathrm{P} 2 \mathrm{p}$ one. The $\mathrm{O} 1 \mathrm{~s}$ region is constituted by two partially overlapping peaks at 532.8 and $533.9 \mathrm{eV}$ due to $\mathrm{C}-\mathrm{O}$ and $\mathrm{P}-\mathrm{O}$ species likely originated by unavoidable impurities and contaminations [27].

Overall the materials surfaces are constituted by elemental phosphorous and graphitic carbon likely interconnected by C-P interphases; minor impurities due to oxidized phosphorous species are 
also present. The carbon particles incorporate defects upon milling whereas elemental phosphorous remains almost unaltered even after $54 \mathrm{~h}$ of ball milling.

\subsection{Electrochemical performance}

Pure phosphorus and P/C-composite electrodes were cycled in sodium half cells employing an optimized liquid electrolyte solution of $1 \mathrm{M} \mathrm{NaPF}_{6}$ in EC:PC (50:50 wt.-\%) with 2 wt.-\% FEC and 5 wt.-\% NaTFSI. As stated above, Al metal foil was selected as current collector, instead of Copper, in order to develop novel P/C-based anodes with reduced cost impact. In order to fit further sustainability requirements, an aqueous electrode processing was conducted by using green binders, As known from the literature [31], compared to the other allotropes (e.g. WP and RP), BP is unaffected by water alone (without $\mathrm{O}_{2}$ ), which cannot cause degradation/ of the black phosphorus since it only weakly physi-sorbs on the BP surface and does not dissociate on it. In contrast, it has been spectroscopically proved that BP seriously and rapidly degrades in presence of oxygen, because the oxidative process involves an easy dissociative chemisorption of $\mathrm{O}_{2}$. The oxidation causes two significant phenomena: i) the turn of the hydrophobic pristine BP surface into hydrophilic; ii) the change of the black Phosphorus electronic structure induced by the $\mathrm{O}_{2}$ adsorption [31]. The former one causes the release of $\mathrm{PH}_{3}$ and $\mathrm{H}_{2}$ and the formation of strong acid as $\mathrm{H}_{3} \mathrm{PO}_{4}$ [22], with consequent safety issues; the latter leads to the degradation of the electronic properties. Both the phenomena are seriously detrimental for the anode electrochemical behavior.

In order to correlate the influence of the Oxygen environment (air or aerated water) on the electrochemical performance of BP-based anodes, the $\mathrm{pH}$ value evolution during the slurry preparation under atmosphere conditions was carefully investigated. Fig.4a shows the abrupt $\mathrm{pH}$ decrease from 8 to 2 when the $\mathrm{P} / \mathrm{C}$ composite is added to the binder solution, corresponding to a significant acidification of the resulting slurry. Such harsh conditions could favor the corrosion of the current collector with consequent failure of the electrochemical performances. Fig.4b plots the galvanostatic cycling at C/20 of an half-cell including a P/C-based anode prepared under ambient condition and exposed to air. It is noticeable that specific capacity higher than $1500 \mathrm{mAh} \mathrm{g}^{-1}$ is delivered during the initial charge/discharge process. However, a rapid failure occurs after only 6 cycles of desodiation/sodiation, confirming the strong effect of oxygen on the BP electrochemistry.

In the lights of these results, the anodes were processed in $\mathrm{O}_{2}$-free (or very low content) conditions, as described in the experimental section. 
Both pure phosphorus and $\mathrm{P} / \mathrm{C}$ composites were galvanostatically cycled at low currents $(\mathrm{C} / 20$, $\left.1 \mathrm{C}=2596 \mathrm{~mA} \mathrm{~g}^{-1}\right)$. Figure 5a reports as an example the resulting differential capacity plot for the $\mathrm{B} / \mathrm{C}$ composite $(\mathrm{t}=54 \mathrm{~h})$ in the explored voltage range. During the cathodic potential scan, one sharp and intense peak is observed at $\sim 0.65 \mathrm{~V}$, followed by a small signal at $0.75 \mathrm{~V}$, corresponding to the sodiation process of BP, whereas on the reverse anodic process, another well-defined peak is present at $0.15 \mathrm{~V}$, which is ascribed to the desodiation from the reduction products. More precisely, such signals indicate the expected well reversible formation of $\mathrm{Na}_{\mathrm{x}} \mathrm{P}$ phase (up to $x=3$ ). Figure $5 \mathrm{~b}$ shows the Nyquist plots collected for the same Sodium half-cell by means of electrochemical impedance spectroscopy at $O C V$, before and after the galvanostatic cycling tests. The spectra have been fitted by using the equivalent circuits model shown in the figure inset, which allows to determine the interface parameters, in terms of charge transfer and diffusion process. The plots show the typical features of this kind of device, presenting a depressed semicircle in the medium frequency domain that describes the charge transfer at the anode and a linear region compatible with the Warburg element representative of the $\mathrm{Na}^{+}$diffusive process. Compared to the pristine electrode $\left(R_{c t}=1220 \Omega\right)$, the charge transfer resistance, $R_{c t}$ at the end of cycling test (after 35 cycles) is lower $\left(R_{c t}=874 \Omega\right.$ ) and this is typically attributed to the increasing of the electrical contact after the activation. Instead, comparable Warburg coefficients, $\sigma_{w},\left(\sigma_{w}=490 \Omega \mathrm{s}^{-0.5}, \sigma_{w}=506 \Omega \mathrm{s}^{-0.5}\right)$ are obtained from the spectra before and after the cycling test, respectively.

Figure 6a shows the first cycle potential profiles of electrodes comprising pure phosphorus ballmilled with ball to powder ratios of 40:1 and 110:1, i.e., lower and higher amounts of black phosphorus, respectively. Both samples depict the typical step-wise sodiation ( $\mathrm{Na}_{\mathrm{x}} \mathrm{P}$ species) with a long potential plateau at around $0.3 \mathrm{~V}$ vs. $\mathrm{Na}$ metal due to the final $\mathrm{Na}_{3} \mathrm{P}$ formation. The higher specific capacity of P-110:1 at around $0.5 \mathrm{~V}$ can be ascribed to more $\mathrm{Na}^{+}$being intercalated into black phosphorus sheets due to higher amounts of BP [32] and, eventually, more severe electrolyte decomposition due to smaller particle size. The higher amount of BP in P-110:1 has only a minor effect on the first specific sodiation capacity, which is higher than the theoretical $2596 \mathrm{mAh} \mathrm{g}^{-1}$ for both electrodes. The first desodiation capacity, however, is significantly higher for P-110:1 compared to P-40:1, i.e., $1532 \mathrm{mAh} \mathrm{g}^{-1}$ and $1127 \mathrm{mAh} \mathrm{g}^{-1}$, respectively. Nonetheless, the cycling performance is not influenced by the amount of BP in the sample, as depicted in fig. 6b, and both cells show severe capacity fading already in the initial cycles.

The capacity retention can be increased when phosphorus is ball-milled with conductive carbon (Super C65). A milling time of $2 \mathrm{~h}$ is already sufficient to push the first cycle desodiation capacity to $2378 \mathrm{mAh} \mathrm{g}^{-1}$ based on the mass of BP, and the capacity retention in the second cycle to $>99 \%$ 
(Figure 6c). In subsequent cycles capacity fades by a shortening of the (de)-alloying plateau, indicating that more and more phosphorus gets inactivated due to active material pulverization. Similar instability is also preliminary observed in case of sodium half-cell including an anode based on P/C composite ball milled for an intermediate time, e.g. 5 hours (BC_5h). Such composite is not fully amorphous like the BC_54h sample, as shown by the XRD pattern in fig.S2, where the main peaks of the BP orthorhombic structure are wider, much less intense but still evident. In this case the capacity is higher than $1600 \mathrm{mAh} \mathrm{g}^{-1}$ based on the composite mass (about $2293 \mathrm{~mA} \mathrm{~h} \mathrm{~g}^{-1}$ based on P mass) during the initial cycles. However, it then abruptly decreases to $600 \mathrm{~mA} \mathrm{~h}$ gcomposite $^{-1}$ ( 793 $\mathrm{mA} \mathrm{h} \mathrm{gP}^{-1}$ ) with an overall capacity fading of $64 \%$ after 30 cycles (see fig.S3a-b).

It is only the significant increase of the ball-milling time, $t$, to $54 \mathrm{~h}$, which drastically reduces the shortening of the alloying plateau and, thus, the capacity fading (Figure 6d). All the composites show more slope like potential profiles compared to pure phosphorus electrodes resulting from the carbon matrix. As evidenced from XPS, BC_54h sample shows defective sites in the Carbon (sp2-defective graphite), which can be a reason for sodiation to start at higher potentials in the BC_54h compared to BC_2h (1.3 V vs. 1.0 V). In fact, it has been shown recently that the presence of structural defects in hard carbons significantly improves Na-ion insertion [30, 31, 32] [33, 34, 35].

Figure 6e depicts that stable cycling is possible for up to 80 cycles with a specific capacity of about $2250 \mathrm{mAh} \mathrm{gP}^{-1}$, based on the BP mass (very close to the theoretical value of $2596 \mathrm{mAh} \mathrm{g}^{-1}$ )) and a desodiation capacity retention of $93.5 \%$ (compared to $17.5 \%$ in case of the composite balled milled for $2 \mathrm{~h}$ ). After 120 cycles, the BC_2h and BC_54h show capacity retentions of around $10 \%$ and $80 \%$, respectively. The formation of phosphorus-carbides is typically ascribed as the main reason for improved electrochemical performance in the case of P-based composites [17] [19]. However, XPS data showed that the amount of carbides in the composites is unaltered when milling times are increased. A different explanation for the enhanced cycling stability might be, for instance, a more homogeneous distribution of carbon and phosphorus in the composite prepared using longer milling times, which is in good agreement with SEM micrographs. In fact, the phosphorus nano-domains allow for a homogeneous embedding into the carbon matrix, which eventually enhances the electronic conductivity of the material and, thus, favors electrochemical insertion of $\mathrm{Na}^{+}$into the nano-domains. Similar experimental observations were discussed in a recent review [5] [7]. The absence of isolated, bulky phosphorus domains as well as the higher degree of amorphization of the BC_54h (as shown by XRD) furthermore prevent excessive volume expansion.

First cycle coulombic efficiency of the BC_54h is above $80 \%$ and stays above $98 \%$ in the first 70 cycles. In subsequent cycles it drops to around $97 \%$, i.e., values which are certainly too low for 
application in a full cell. When capacities are calculated based on the weight of the $\mathrm{P} / \mathrm{C}$ composite (active material) and the whole electrode coating, initial desodiation capacities are above $1500 \mathrm{mAh} \mathrm{g}_{\text {composite }}{ }^{-1}$ and $750 \mathrm{mAh} \mathrm{gelectrode}^{-1}$, respectively (Figure 6f). By considering the value based on the composite mass and the $\mathrm{P} / \mathrm{C}$ ratio, it is possible to isolate the sodiation contribution of BP in the composite, which results to be dominant [36]. As shown in fig.6e, capacity higher than $2250 \mathrm{mAh}$ $\mathrm{g}_{\mathrm{P}}^{-1}$ based on the $\mathrm{BP}$, is obtained, which is very close to the theoretical value. The $\mathrm{Na}$ insertion/deinsertion capacity of Super C65 alone is, in fact, only 100-150 mAhg ${ }^{-1}$ at the same investigate current density [37] and its contribution counts for about 30-45 $\mathrm{mAh} \mathrm{g}^{-1}$

Despite a decrease to $97 \%$ of the coulombic efficiency, the observed capacity is significantly higher than the ones for graphite in commercial lithium-ion batteries and for hard carbons in state of the art sodium-ion batteries. Furthermore, to the best of our knowledge, such values are unprecedented since achieved on aluminum current collector, while most studies on P-based anodes in common literature show results on copper current collector (See Table.S1). Recently, Dahbi et al. described a BP/acetylene black composite anode for NIBs, casted on Al foil [12]. The resulting electrode delivered specific capacity of $1500 \mathrm{~mA} \mathrm{~h} \mathrm{~g}$ 1, based on $\mathrm{P}$ mass, which seriously falls down to $800 \mathrm{mAh} \mathrm{g}^{-1}$ over 25 cycles. Such electrochemical properties were discussed in terms of interface instability and no reference to the slurry optimization with respect to the current collector was discussed. Some improvements were observed by adding proper electrolyte additives, as fluoroethylene carbonate (FEC) or vinylene carbonate (VC), which are particularly efficient for the Na cells by forming more stable SEI. In this case the capacity fading over cycling was limited to $91 \%$. for the initial 25 cycles. [12].

Figure 7 shows post mortem SEM-FIB analysis of the BC_54h sample. The cross section of a pristine electrode (Figure 7a) reveals that the electrode is highly porous, and the coating is around 15 $\mu \mathrm{m}$ thick. The active material particles are rather inhomogeneously distributed in size, with large domains of up to $3 \mu \mathrm{m}$. EDX mapping of the cross sections (Figure 7b) confirms that phosphorus rich domains vary in size from nm to $\mu \mathrm{m}$ scale. However, carbon is present in the whole cross section of the electrode, with high signal originating from the conductive additive, and low signal from carbon present in the composite (i.e., in the phosphorus rich domains). This indicates that the composite forms secondary particles composed of phosphorus-carbon composite nanoparticles, which is in good agreement with SEM micrographs (see Figure 2).

The cycled electrode is much less porous (Figure 7c), indicating that porosity partially helps to buffer the large volume expansion of phosphorus. Coating thickness of the cycled electrode, however, is $>40 \mu \mathrm{m}$ and, thus, electrode volume expansion is not fully prevented. This could be an explanation 
for the rather poor coulombic efficiency (see Figure 6f), i.e., continuous exposure of fresh electrode surface and, hence, continuous electrolyte decomposition. Furthermore, it appears that the coating layer detaches from the current collector, eventually leading to inactivation of the active material coating layer. On the other hand EDX maps of the cycled electrode (Figure 7d) clearly show that the secondary particle structure stays intact even after 135 cycles, which explains the excellent cycling performance of the BC_54h composite.

\section{Conclusions}

$\mathrm{P} / \mathrm{C}$ composites were successfully synthetized via high energy ball milling at a rate of $500 \mathrm{rpm}$, spheres/material ratio of 30/1 and two different times: 2 hours (BC_2h) and 54 hours (BC_54h). All the electrochemical characterizations were performed on aluminum current collector thanks to the exclusion of oxygen during aqueous electrode processing. The active materials were investigated by XRD, XPS, SEM-EDS, post-mortem SEM and galvanostatic cycling.

A ball milling time of $54 \mathrm{~h}$ resulted in a phosphorus-carbon composite delivering initial specific charge capacities of around $2250 \mathrm{mAh} \mathrm{gP}^{-1}$ and excellent capacity retention of around $80 \%$ at $\mathrm{C} / 20$ after 120 cycles. Three phenomena were identified to synergistically improve the electrochemical performance if compared to a composite ball milled for $2 \mathrm{~h}$ : (i) longer milling times and, thus, higher energies lead to an almost fully amorphous system which is able to partially buffer the volume expansion, (ii) decrease of the phosphorus particles dimensions $(<500 \mathrm{~nm})$, leading to homogeneous distribution of phosphorus and carbon within the composite secondary particles without isolated Pbased domains, and finally (iii) the introduction of defects in the carbon matrix, enabling Na-ion insertion at high potentials and enhancing overall electrochemical performance.

The presented phosphorus-carbon composite outperforms state of the art hard carbons in SIBs and graphite in LIBs in terms of specific and volumetric capacity, and the good capacity retention especially in combination with aluminum current collector - are certainly a major step towards successful future commercialization of SIBs.

In conclusion, the proper design of the composite is a very good strategy to overcome the still open challenges of P-based anodes in NIBs, which are all substantially related to the structural instability of black phosphorus over cycling. Future works to further increase the anode stability, rate capability and, last but not least, the insertion/extraction reversibility might point towards, for instance, the investigation of hard carbons as composite component alternative to carbon black, in 
order to enhance the surface defective sites, which are beneficial for the Na storage, and the use of other green binders, with self-healing capability to limit the $\mathrm{P}$ volume expansion.

\section{Acknowledgements}

The authors gratefully acknowledge Dr. Emanuele Vigo for his support during the samples preparation. Financial support from the Italian Ministry of University and Research (MIUR) through grant "PRIN 2017, 2017MCEEY4, "Towards sustainable, high-performing, all-solid state sodium ion batteries" is also gratefully acknowledged. 


\section{References}

[1] J.-M. Tarascon, M. Armand, Nature, 414, 359 (2001).

[2] M. Armand, J.-M. Tarascon, Nature, 451, 652 (2008).

[3] B. Scrosati, J. Garche, J. Power Sources, 195, 2419 (2010).

[4] C. Vaalma, D. Buchholz, M. Weil, S. Passerini, Nat. Rev. Mater., 3, 1 (2018).

[5] S. Zhang, H. Ying, R. Guo, W. Tao Yang, W.-Q. Han, J. Phys. Chem. Lett., 10, 6446 (2019).

[6] S. Zhang, X.-Y. Li, W. Yang, H. Tian, Z. Han, H. Ying, G. Wang, W.-Q. Han, ACS Appl. Mater. Interfaces, 11, 42086 (2019).

[7] Y. Fu, Q. Wei, G. Zhang, S. Sun, Adv. Energy Mater., 8, 1702849 (2018).

[8] R. Gusmao, Z. Sofer,, M. Pumera, Angew. Chem. Int. Ed., 56, 8052 ( 2017).

[9] L.E. Marbella, M.L. Evans, M.F. Groh, J. Nelson, K.J. Griffith, A.J. Morris, C.P. Gray, J. Am. Chem. Soc., 140, 7994 (2018).

[10] M. Mayo, K.J. Griffith, C.J. Pickard, A.J. Morris, Chem. Mater., 28, 2011 (2016).

[11] T. Chen, P. Zhao, X. Guo, S. Zhang, Nano Lett,, 17, 2299 (2017).

[12] M. Dahbi, N. Yabuuchi, M. Fukunushi, K. Kubota, K. Chihara, K. Tokiwa, X.-F Yu, H. Ushiyama, K. Yamashita, J.-Y. Son, Y.-T. Cui, H. Oji, S. Komaba, Chem. Mater., 28, 1625 (2016).

[13] J. Qian, X. Wu, Y. Cao, X. Ai, H. Yang, Angew. Chem., 125, 4731 (2013).

[14] N. Yabuuchi, Y. Matsuura, T. Ishikawa, S. Kuze, J.Y. Son, Y.-T. Cui, H. Oji, S. Komaba, ChemElectroChem., 1, 580 (2014).

[15] W. Lu, H. Zhi, X. Yu, Energy Storage Materials, 16, 290 (2019).

[16] X. Qin, B. Yan, J. Yu, J. Jin, Y. Tao, C. Mu, S. Wang, H. Xue, H. Pang, Inorg. Chem. Front., 4, 1424 (2017).

[17] C. Ferrara, E. Vigo, B. Albini, P. Galinetto, C. Milanese, C. Tealdi, E. Quartarone, S.

Passerini, P, Mustarelli, Acs Appl. Energy Mater., 2, 2794 (2019). 
[18] G.-L-. Xu, Z. Chen, G.-M. Zhong, Y. Liu, Y. Yang, T. Ma, Y. Ren, X. Zuo, X.-H. Wu, X. Zhang, K. Amine, Nano Lett., 16, 3955 (2016).

[19] H. Liu, L. Tao, Y. Zhang, C. Xie, P. Zhou, H. Liu, R. Chen, S. Wang, ACS Appl. Mater. Interfaces, 9, 36489 (2017).

[20] S. Haghighat-Shishavan, M. Nazarian-Samani, M. Nazarian-Samani, H.-K. Roh, K.-Y. Chung, B.-W. Cho, S. F. Kashani-Bozorg, K.-B. Kim, J. Mater. Chem. A., 6, 10121 (2018).

[21] X. Wu, W. Zhao, H. Wang, X. Qi, Z. Xing, Q. Zhuang, Z. Ju, J. Power Sources, 378, 460 (2018).

[22]. C. Marino, M. El Kazzi, E.J. Berg, M. He, C. Villevieille, Chem. Mater., 29, 7151 (2017).

[23] W. Xiao, Q. Sun, M. N. Banis, B. Wang, J. Liang, A. Lushington, R. Li, X. Li, T.-K. Sham, X. Sun, ACS Appl. Mater. Interfaces, 11, 30763 (2019).

[24] Nilges, T.; Schmidt, P.; Weihrich, R. Phosphorus: The Allotropes, Stability, Synthesis and Selected Applications. Encyclopedia of Inorganic and Bioinorganic Chemistry; Wiley \& Sons (2018).

[25] M. Ruck, D. Hoppe, B. Wahl, P. Símon, Y. Wang, G. Seiferty, Angew. Chem. Int. Ed., 44, 7616 (2005).

[26] Ingegärd Johansson, P. Somasundaran, Handbook for Cleaning/Decontamination of Surfaces, Elsevier Science B.V., 2007, ISBN 9780444516640, 10.1016/B978-0-444-51664-0.50030-9. [27] NIST X-ray Photoelectron Spectroscopy Database, NIST Standard Reference Database Number 20, National Institute of Standards and Technology, Gaithersburg MD, 20899, 2000, doi:10.18434/T4T88K.

[28] M. Carboni, J. Manzi, A.R. Armstrong, J. Billaud, S. Brutti, Y. Younesi, ChemElectroChem., 6, 1745 (2019).

[29] H. Lyu, B. Gao, F. He, C. Ding, J. Tang, J.C. Crittenden, ACS Sustainable Chemistry \&

Engineering, 5, 9568 (2017). 
[30] I.Capone, K.Hurlbutt, A.J.Naylor, A.W.Xiao, M. Pasta, Energy Fuels, 33, 45651 (2019).

[31] Y. Huang, J. Qiao, K. He, S. Bliznakov, E. Sutter, X. Chen, D. Luo, F. Meng, D. Su, J. Decker, W. Ji, R.S. Ruoff, P. Sutter, Chem. Mater., 28, 8330 (2016).

[32] J. Sun, H.-W. Lee, M. Pasta, H. Yuan, G. Zheng, Y. Sun, Y. Li, Y. Cui, Nat. Nanotechnol., 10, 980 (2015).

[33] C. M. Ghimbeu, J. Gorka, V. Simone, L. Simonin, S. Martinet, C. Vix-Guterl, Nano Energy, 44, 327 (2018).

[34] Z. Li, Y. Chen, Z. Jian, H. Jiang, J.J. Razinik, W. F. Stickle, J.C. Neuefeind, X. Ji, Chem. Mater., 30, 4536 (2018)

[35] B. Zhang, C.M. Ghimbeu, C. Laberty, C.V.-Guterl, J.M. Tarascon, Adv. Energy Mater.,

6, 1501588 (2016).

[36] W. Li, Z. Yang, M. Li, Y. Jiang, X. Wei, X. Zhong, L. Gu, Y.Yu, Nano Lett. 16, 1546 (2016).

[37] P. Kumar Datta, A. Gosh, S. Mitra, in: Sodium-ion batteriy anode stabilization. Ch.7. Nanomaterial for Electrochemical Energy Storage Devices, P. Roy and S.K. Srivastava Eds., (2019) John Wiley \& Sons (USA). 

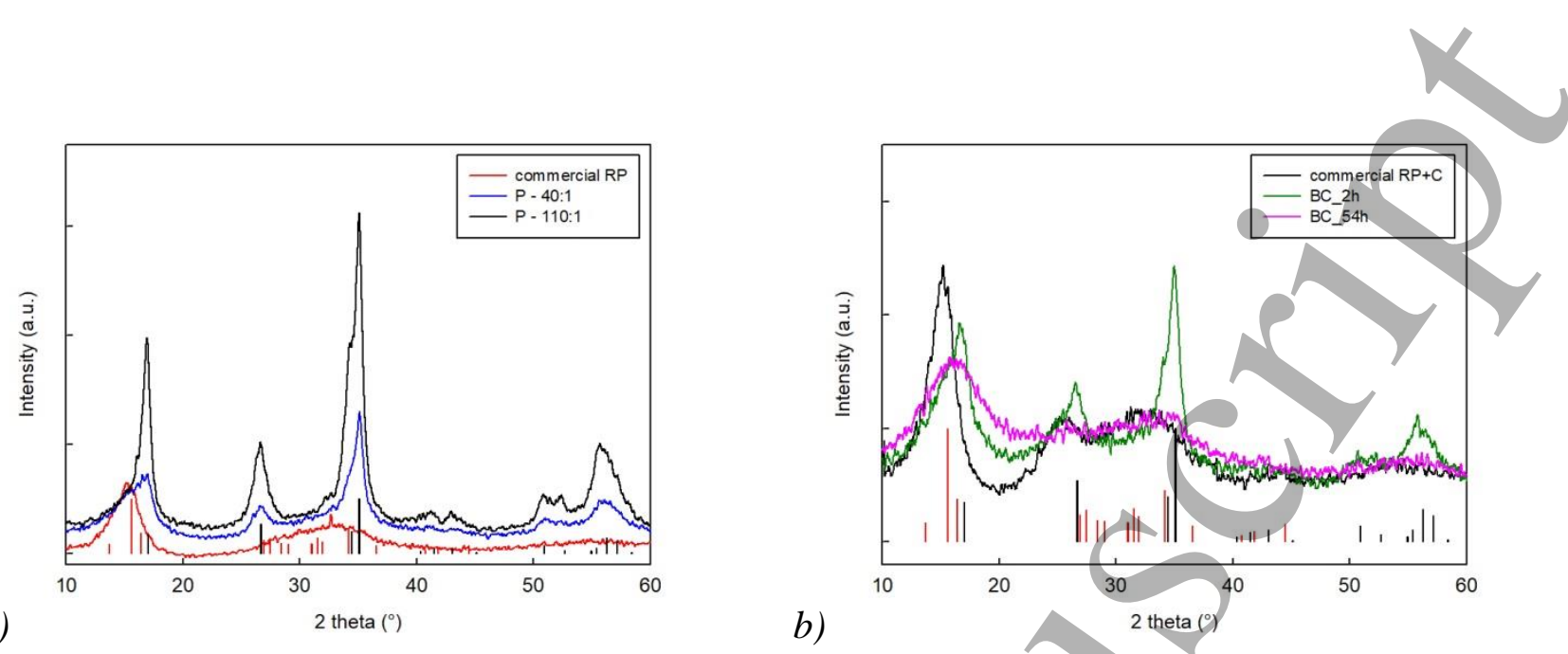

Figure 1. Experimental XRDP of pure phosphorus (a) and the P/C composites (b), together with those of commercial RP and a mechanical mixture of RP and C prior to HEBM added for comparison. Vertical bars refer to the Bragg intensities related to RP (red) and BP (black) as reported in the PDF cards 44-0906 and 76-1958, respectively. 


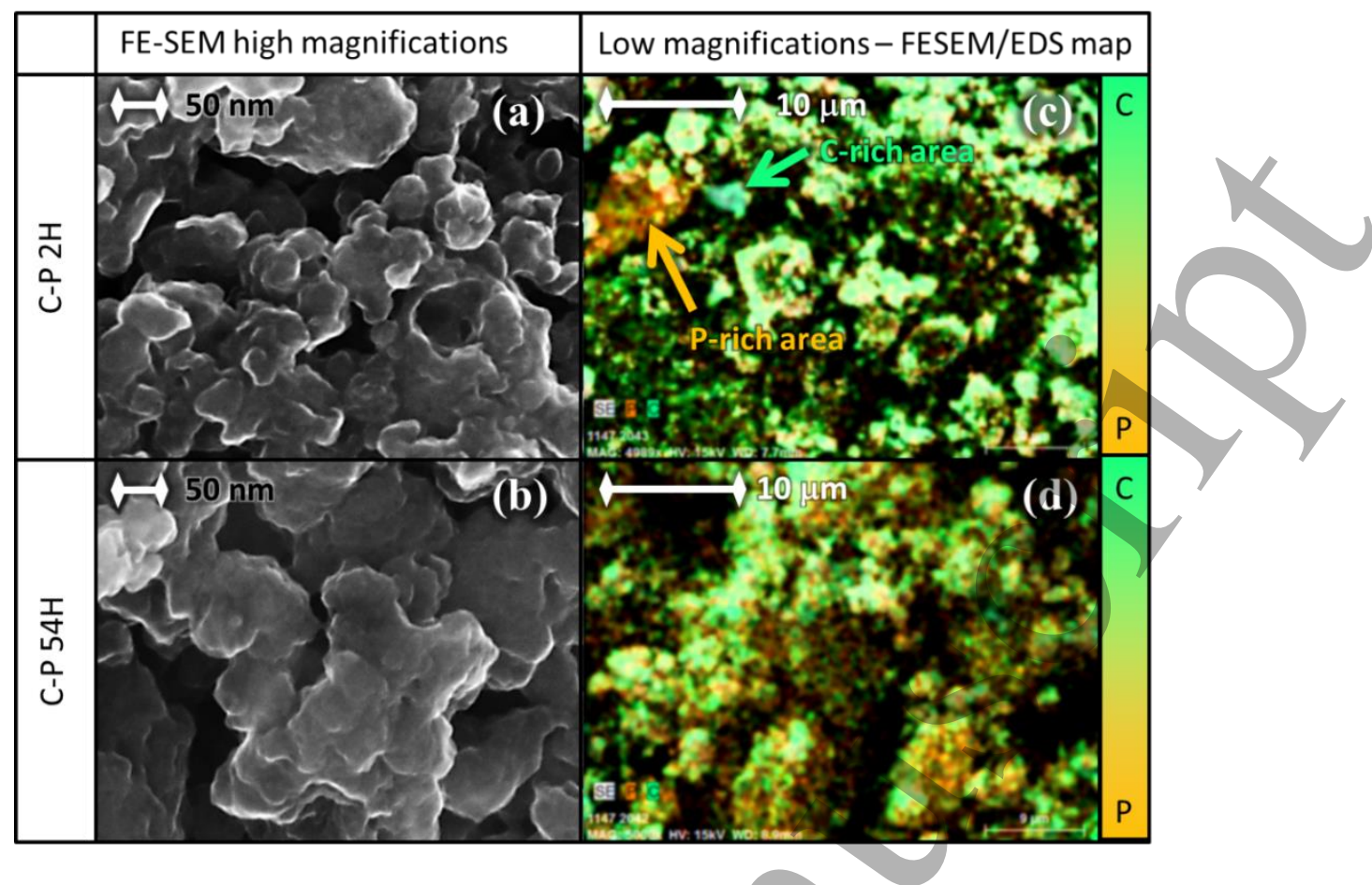

Figure 2. (a-b) FE-SE micrographs at high magnification and (c-d) combined FE-SEM/EDX areal maps of the two P/C- composite materials ball milled 2 and 54 hours, respectively. 

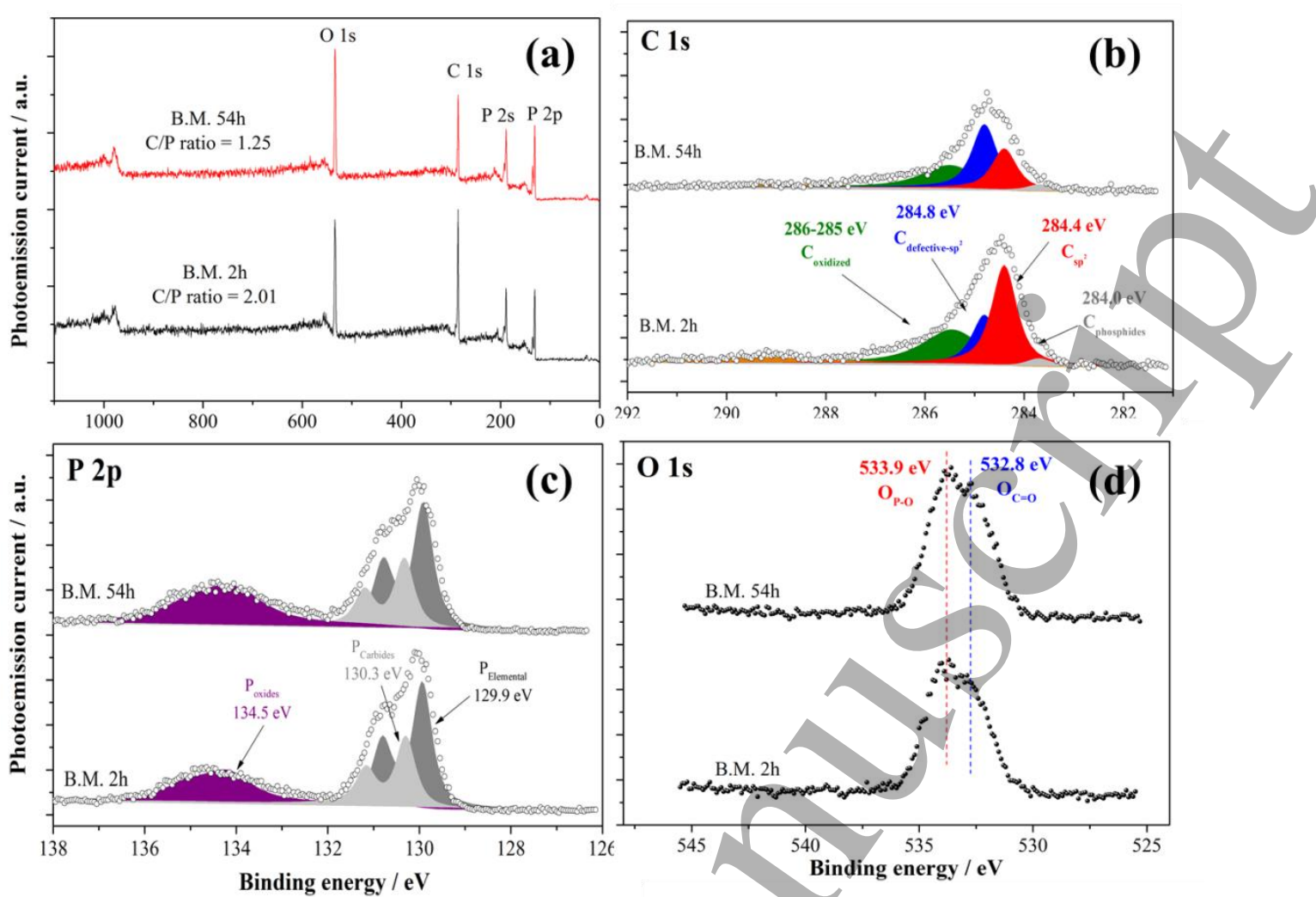

Figure 3. (a) Wide XP spectra and details of the (b) C 1s, (c) P 2p and (d) O 1s regions measured for the two P/C- composite materials ball milled 2 and 54 hours, respectively. 
a)

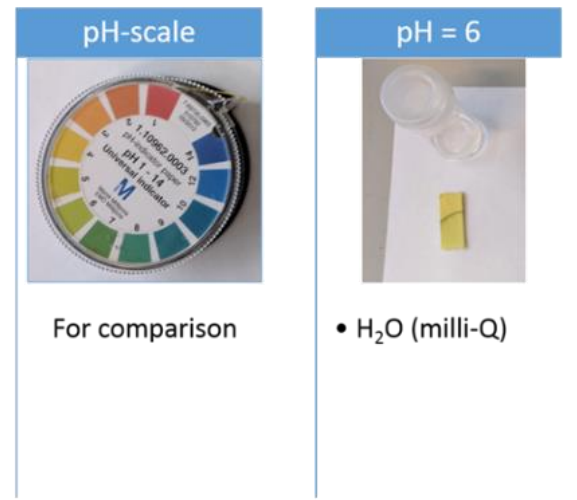

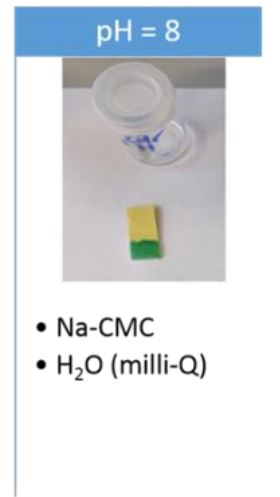
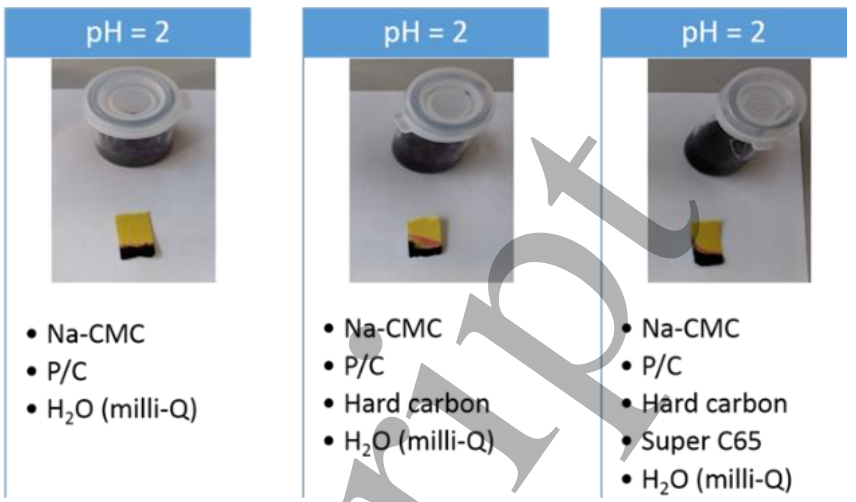

b)

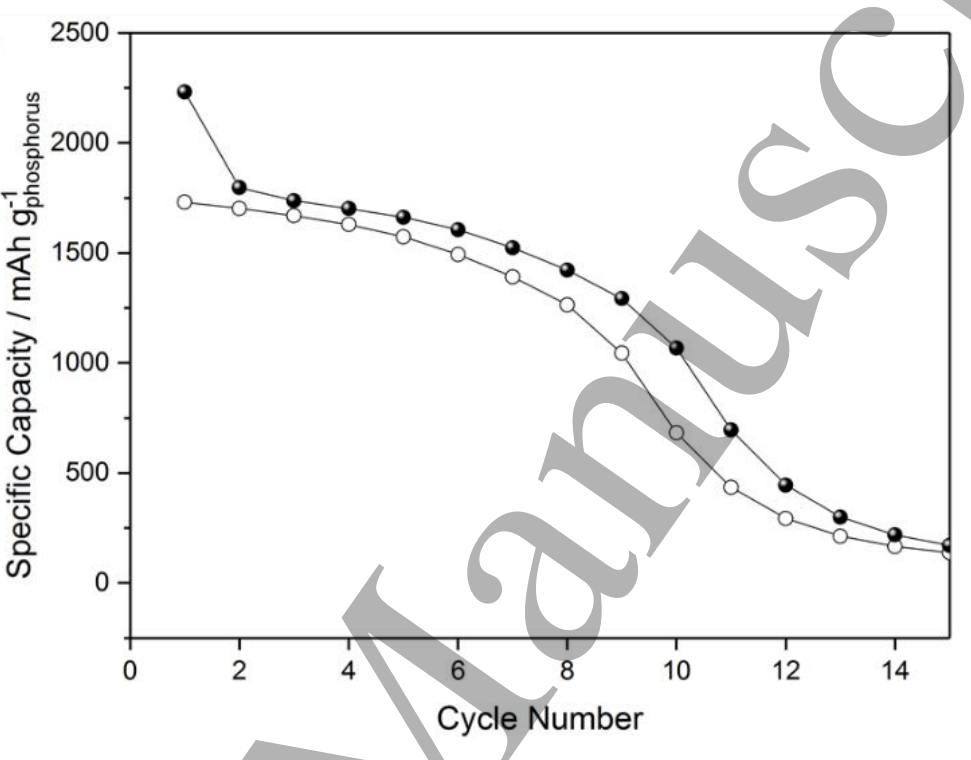

Fig. 4: a) PH value evolution upon slurry preparation under ambient atmosphere conditions. The slurry turns highly acidic after addition of P/C-composite exposed to air. b) Cycling performance of a P/C-composite electrode processed under ambient atmosphere conditions. 


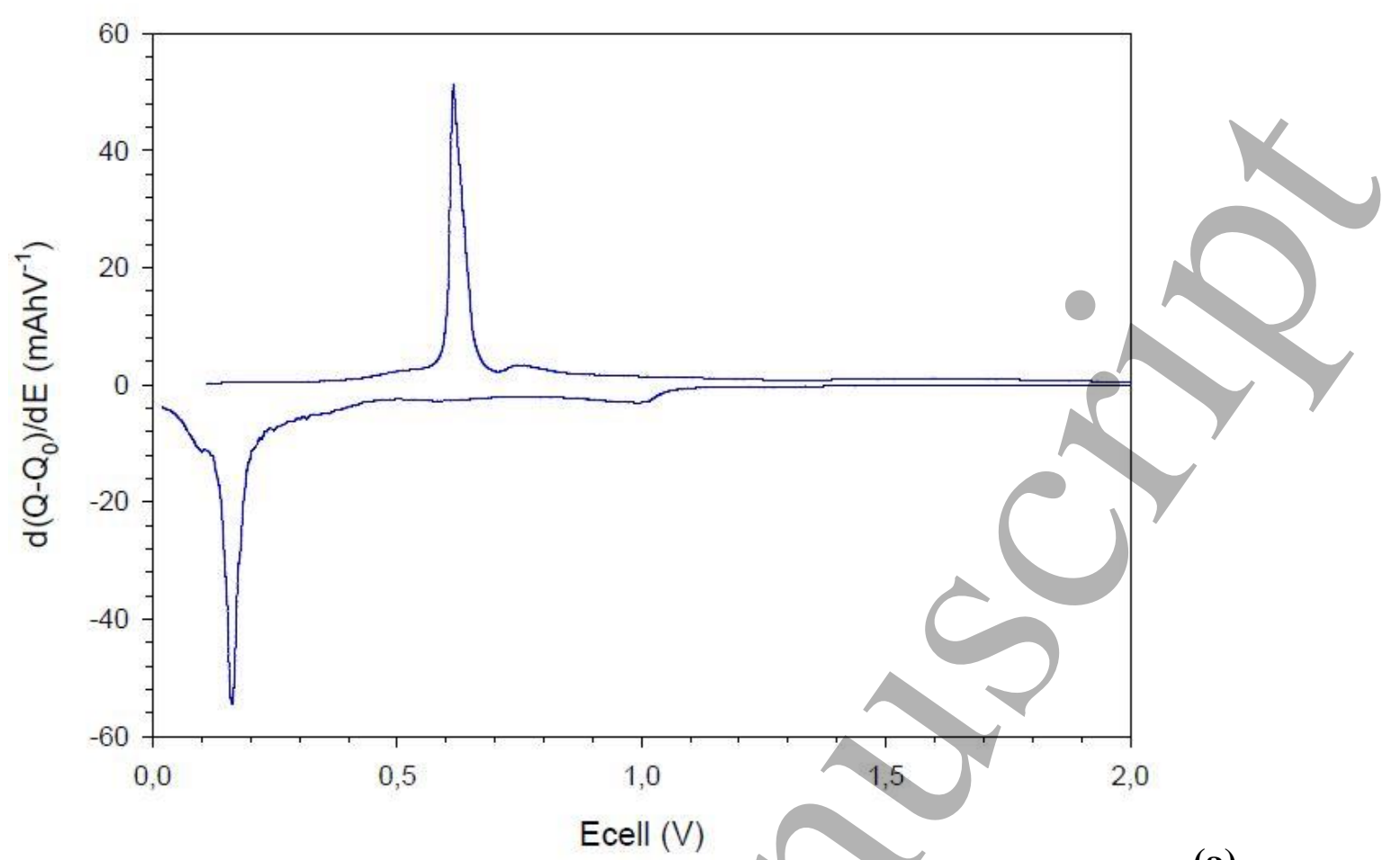

(a)

(b)

Fig.5: (a) Differential capacity behavior between 0.02 and $2 \mathrm{~V}$ obtained from the galvanostatic cycling at C/50 for the sodium half-cell including BC_54h as composite anode. (b) Nyquist plots collected by electrochemical impedance spectroscopy for the sodium half-cell including BC_54h as composite anode at OCV before and after the galvanostatic cycling tests. The inset shows the equivalent circuits model used to fit the plot. $R_{2}$ is the charge transfer resistance $R_{c t}$. 
a)

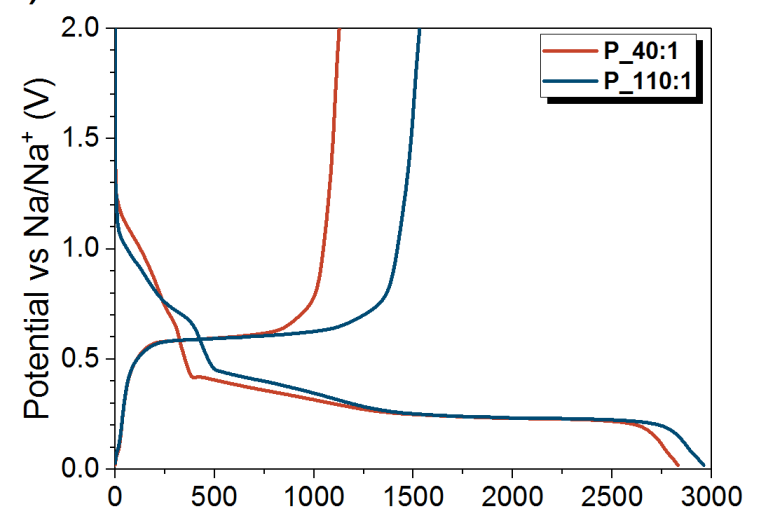

c)

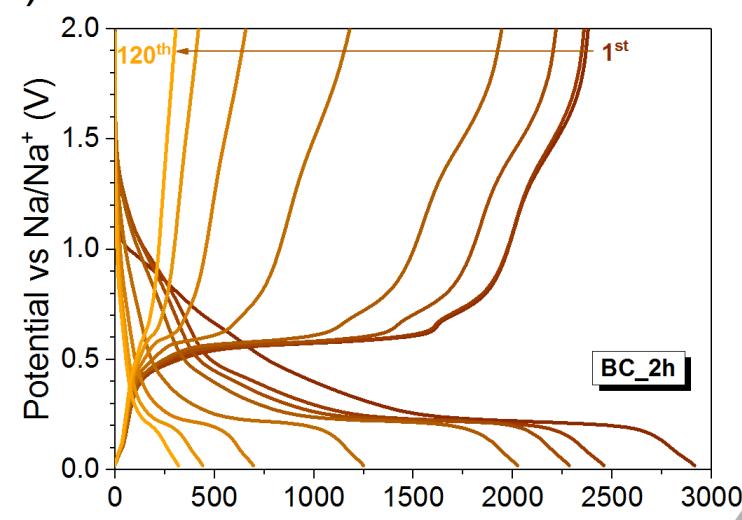

e) Specific Capacity (mAh g ghosphorus)

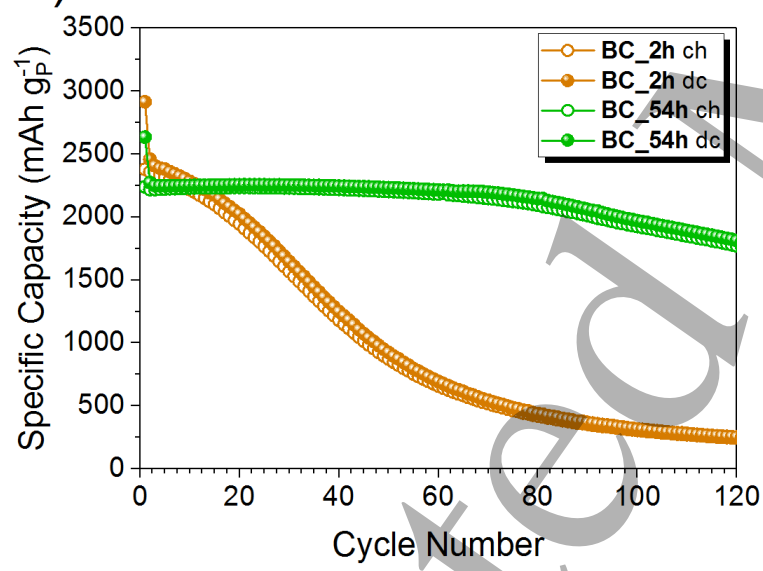

b)

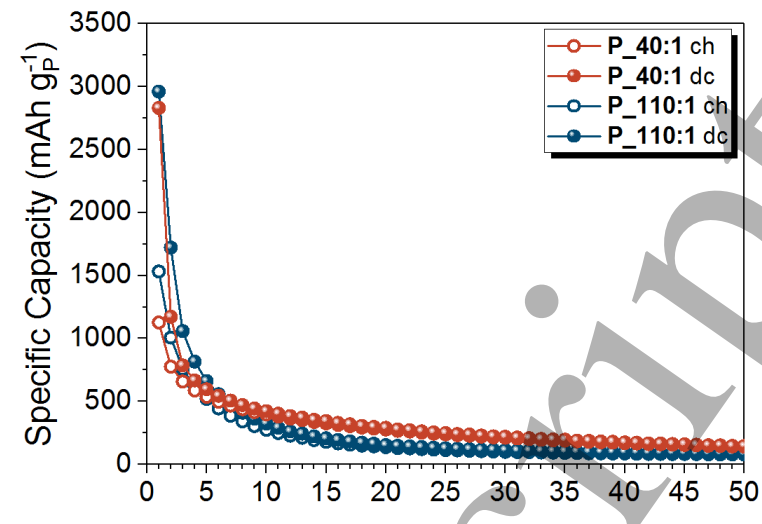

d)

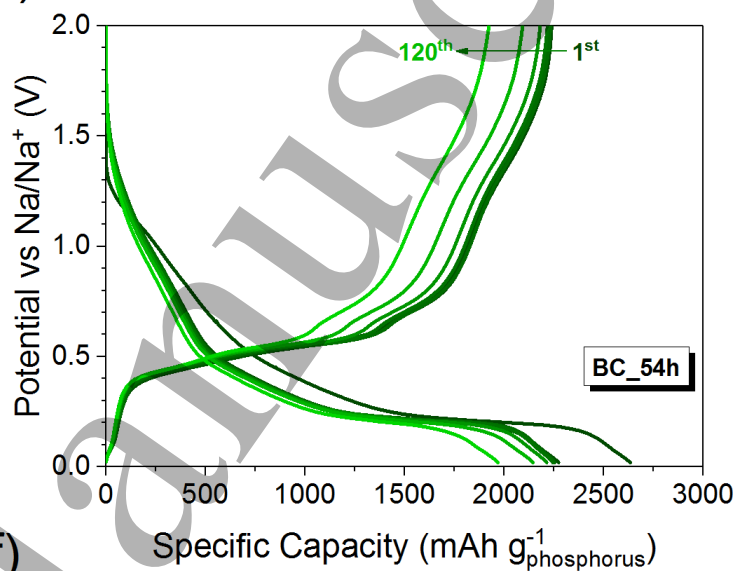

f)

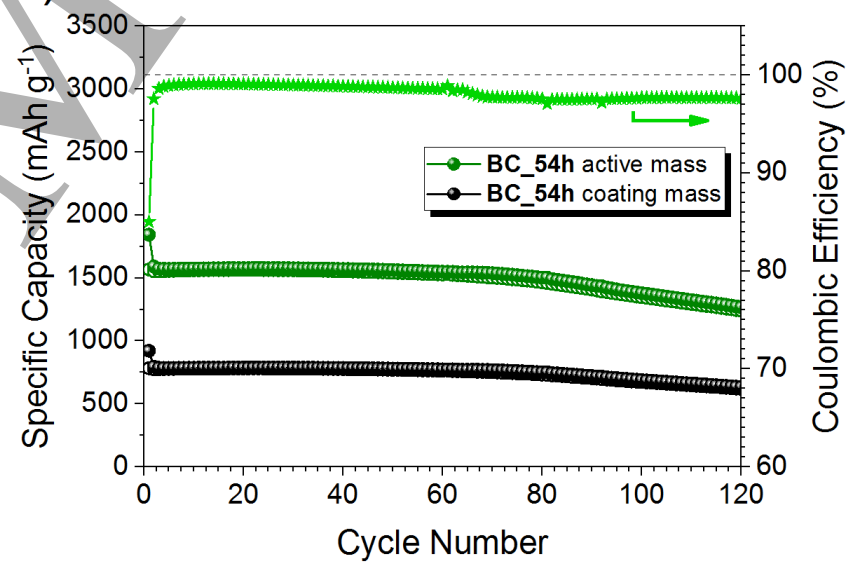

Figure 6: Electrochemical characterization of pure P and the P-C-composite. (a) First cycle potential profiles of electrodes with phosphorus ball-milled under different conditions and (b) corresponding cycling performance. Potential profiles of the P/C-composite ball-milled for (c) $2 \mathrm{~h}$ and (d) $54 \mathrm{~h}$ and (e) corresponding cycling performance. (f) Cycling performance of the P/C-composite ball milled for $54 \mathrm{~h}$ based on the mass of the active material and the whole electrode coating. Electrolyte: $1 \mathrm{M} \mathrm{NaPF}_{6}$ in EC:PC $(1: 1 \mathrm{wt} . \%)+5$ wt.- $\%$ NaTFSI + 2 wt.-\% FEC. Applied current rates: 1st cycle C/50, consecutive cycles C/20 $\left(1 \mathrm{C}=2596 \mathrm{~m} \mathrm{~A} \mathrm{~g}^{-1}\right)$. 

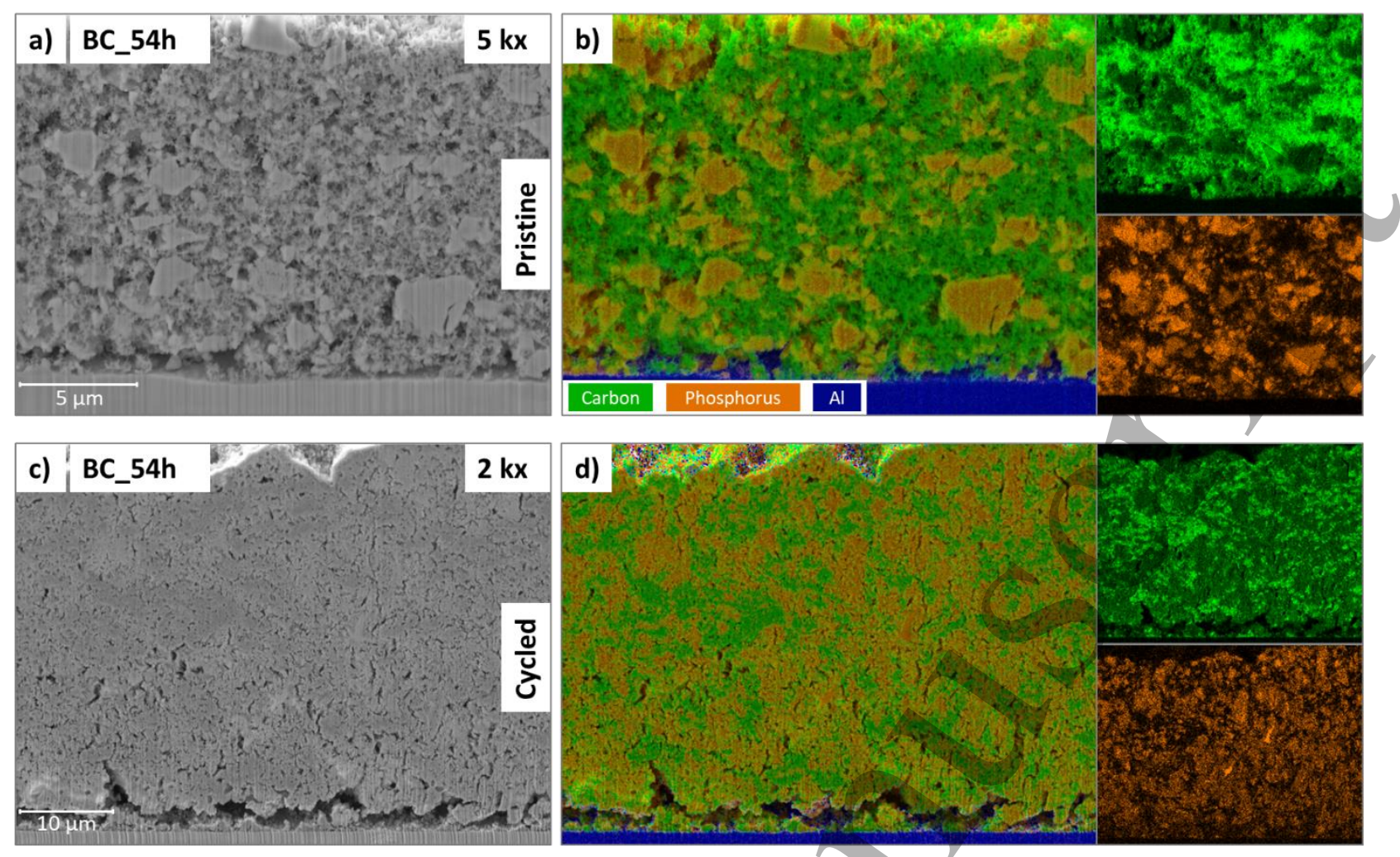

Figure 7: Post-mortem SEM-FIB/EDX characterization. (a) SEM-FIB cross section of a pristine BC_54h composite electrode and (b) corresponding EDX mapping. (c) SEM-FIB cross section of a cycled BC_54h composite electrode (after 135 cycles) and (d) corresponding EDX mapping. 